Cita bibliográfica: Arias González, M. C. (2019). El paisaje en la conformación de destinos turísticos en el litoral mexicano. Estudio de caso Cancún. Investigaciones Turísticas (17), pp. 168-188. http://dx.doi.org/10.14198/ INTURI2019.17.08

\title{
El paisaje en la conformación de destinos turísticos en el litoral mexicano. Estudio de caso Cancún
}

\section{The role of landscape in shaping tourist destinations on the Mexican coastline. Case study: Cancun}

María del Consuelo Arias González (iD, Instituto Politécnico Nacional, México. consueloag@hotmail.com

\section{RESUMEN}

Como parte de una disertación doctoral, y mediante una investigación teórica, descriptiva y observacional, a través de los métodos descriptivo correlacional y teórico experimental, se reconoce el papel protagónico del paisaje, y sus recursos, en la creación y consolidación de destinos turísticos litorales, particularmente para el caso de Cancún, y se plantea la necesidad de su conservación para asegurar su continuidad y la del turismo en el destino. Aprovechando la belleza del paisaje, sus playas vírgenes, sus áreas selváticas y la baja densidad de población, el territorio de Cancún fue elegido para crear un sitio turístico de alta densidad. La construcción de la infraestructura turística modificó el paisaje que le dio origen, dando paso a uno nuevo, antropizado, pero con una fisonomía particular que lo ha mantenido como uno de los predilectos para el turismo internacional. Sin embargo, es importante analizar cómo el desarrollo de un destino puede llevar a la transformación del territorio en periodos tan cortos y como a pesar de seguir conservando su valor para el turismo, en el corto o en el mediano plazo, las transformaciones del paisaje pueden ser tan profundas que impidan tener paisajes de calidad o excepcionalidad para ser ofertados por el turismo.

Palabras clave: Paisaje; Destinos turísticos; Litoral mexicano; Cancún; Turismo litoral

\section{ABSTRACT}

As part of a doctoral dissertation, and through theoretical, descriptive and observational research based on correlational descriptive and experimental theoretical methods, the leading role of the landscape and its resources in the creation and consolidation of coastal tourist destinations is examined, particularly in the case of Cancun. The study also considers the need for the conservation of the landscape in order to ensure its continuity and that of tourism in the destination. Due to the beauty of the landscape, its virgin beaches, its jungle areas and the low population density, the territory of Cancun was chosen to create a high 
density tourism resort. The construction of the tourism infrastructure modified the original landscape of the destination, giving rise to a new one, anthropized, but with a unique physiognomy that has allowed it to remain among the favorite destinations of international tourism. However, it is important to analyze how the development of a destination can lead to the transformation of the territory in such short periods of time and, in spite of continuing to preserve its value for tourism, in the short or medium term, landscape transformations can be so profound that they impede the existence of quality or exceptional landscapes to be offered by tourism.

Keywords: Landscape; Tourist destinations; Mexican coastline; Cancun: Coastal tourism

\section{INTRODUCCIÓN}

La belleza escénica de un lugar resulta de valor para el uso turístico recreativo; los recursos naturales y culturales se incorporan como sustento de las actividades turísticas, y dichos recursos integran y componen el paisaje (Ricci, Fernández, Valenzuela y Castronovo, 2010). El paisaje es uno de los recursos más importantes para el desarrollo de destinos turísticos (Fyhri, Jacobsen y Tømmervik, 2009; Soares, Medeiros y Sales Filho, 2014), particularmente para los destinos que sustentan su oferta en el sol y la playa (Semeoshenkova y Newton, 2015). Y es, también, el principal valor de los sitios que viven del turismo (Nogué, 2010).

Sin embargo, el desarrollo del turismo conlleva la transformación del paisaje. El grado de transformación depende de la intensidad de uso que se haga del territorio, del modelo de desarrollo turístico y del tipo de infraestructura construida. Los destinos turísticos litorales se han caracterizado por la construcción de infraestructura y equipamiento a gran escala, consumiendo de forma drástica el territorio y transformando el paisaje de forma acelerada. Esta situación puede llevar al agotamiento del recurso y, así, a la pérdida de su calidad y su excepcionalidad, poniendo en riesgo la sostenibilidad del propio destino turístico.

En México, el turismo es considerado una de las actividades prioritarias para el crecimiento económico del país al contribuir con el 8.7\% del Producto Interno Bruto (Secretaría de Turismo, 2016), y el turismo litoral uno de los principales productos. Cancún es el destino turístico más importante de México a nivel internacional, situación reflejada en los $\$ 4,700.64$ millones USD de derrama económica en 2016, los 187 hoteles de la zona hotelera con 35,549 cuartos reportados para abril de 2017, el movimiento de pasajeros en su aeropuerto, considerado el segundo con mayor tráfico de pasajeros en México y el primero en vuelos internacionales (H. Ayuntamiento de Benito Juárez, 2014).

Cancún es la cabecera del municipio Benito Juárez, en el Estado de Quintana Roo, México, se localiza entre las coordenadas (8648'21.63" O, 21ำ12'47.62"N) a (8649'30.82"

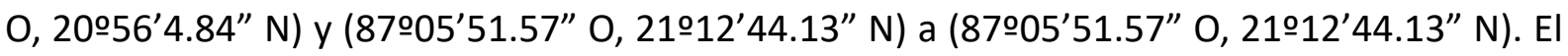
municipio colinda al norte con el municipio de Isla Mujeres, al este con el Mar Caribe, al oeste con el municipio Lázaro Cárdenas y al sur con el municipio de Puerto Morelos, de nueva creación; tiene una extensión de $983,180 \mathrm{~km}^{2}$ con una altitud media de $10 \mathrm{~m}$ sobre el nivel del mar (Inegi, 2010). 
Para el desarrollo del centro turístico se consideró la belleza paisajística del territorio como uno de sus principales recursos. A lo largo de las cuatro décadas y media de vida del destino se ha transformado el paisaje original, dando paso a uno con una fisonomía particular que lo mantiene posicionado en el mercado internacional. Sin embargo, sus tendencias de crecimiento podrían poner en riesgo la conservación del recurso y disminuir su calidad, ocasionando una disminución en los flujos turísticos y la derrama económica. Así, en este documento se reconoce el papel protagónico del paisaje, y sus recursos, en la creación y consolidación de destinos turísticos litorales y se plantea la necesidad de su conservación para seguir sosteniendo la actividad turística en el destino.

\section{EL PAISAJE EN LA CONFORMACIÓN DE DESTINOS TURÍSTICOS}

\subsection{El Paisaje}

Etimológicamente el término paisaje proviene del latín pagus, que significa país (Cancer, 1994: 18; Santos y Ganges, 2003: 43). Entre 1600 y 1900, en lengua holandesa, el paisaje estuvo referido a la pintura, y no es hasta el siglo XX que se convierte en un concepto académico (Contreras, 2005:59), objeto de investigación de diferentes disciplinas teniendo como elemento en común el territorio. De acuerdo con el Convenio Europeo del Paisaje, hace referencia a cualquier parte del territorio tal como lo percibe la población, cuyo carácter sea el resultado de la acción y la interacción de factores naturales y/o humanos (Consejo de Europa, 2000, artículo $1^{\circ}$ ); mientras que en la Iniciativa Latinoamericana del Paisaje se refiere al Espacio Vital donde la sociedad se relaciona con la naturaleza con connotaciones ambientales, culturales, históricas, políticas y económicas, siendo todo territorio paisaje, no solo aquellos excepcionales y monumentales, sino también los cotidianos (LALI Iniciativa Latinoamericana del Paisaje, 2018).

Como sistema territorial, el paisaje se refiere a la composición e integración de diferentes elementos formados a partir de la influencia de los procesos naturales y de la actividad modificadora de la sociedad humana, que se encuentran en permanente interacción y que se desarrollan históricamente (Lombardo y Casella, 1997 en Barreto y Rodrigues, 2012:144). Como sistema ecológico, se refiere al conjunto procedente de la agregación de los caracteres físicos, del medio físico, y de los rasgos físicos del medio biótico (Gómez Orea 1985 y 1992 en Cancer, 1994; Aguiló, 1961 en Sotelo, 1992). En su enfoque cultural se refiere al resultado de la transformación colectiva de la naturaleza y del equilibrio entre los elementos naturales y antrópicos (Nogué, 1989: 41-42).

En su enfoque artístico, el paisaje es la figura estéticamente construida (Covarrubias, 2015: 54), una elaboración cultural a partir de criterios estéticos (Manuel, 2006: 79) y, para que el territorio sea paisaje, requiere ser mirado por un sujeto capaz de interiorizarlo artísticamente (Lindón, 2007). Finalmente, en su enfoque perceptivo, es el producto de una operación perceptiva del medio físico; es decir, es un elemento subjetivo del medio ambiente (Roger, 2013: 142), la realidad del espacio terrestre percibido y diferenciado por los sentidos (JeanRobert Pitte en Roger, 2013: 139). 
En este documento, se entiende por paisaje el territorio, delimitado geográficamente, que presenta una fisonomía y unas características particulares, en donde interactúan elementos físicos, bióticos y abióticos, y donde se desarrollan actividades antrópicas. Y por recursos paisajísticos, aquellos elementos singulares de un paisaje o grupo de éstos que definen su individualidad y que tienen un valor visual, ecológico, cultural y/o histórico (Artículo 32 del RPCV en Meseger, 2010). Es importante señalar que el paisaje también provee servicios ambientales de aprovisionamiento, regulación, culturales y de soporte asociados con el mantenimiento de la biodiversidad y los ecosistemas, que son de interés para las generaciones presentes y futuras (Bottero, 2011: 168); de ahí la importancia de su conservación.

\subsection{El Paisaje como recurso turístico}

El turismo necesita de los recursos paisajísticos para la promoción y presentación de bienes y servicios. El paisaje es el recurso más importante para el desarrollo del turismo litoral (Botero, Anfuso, Williams, y Palacios, 2013; Iglesias et al., 2018; Nogué, 2010; Soares, Medeiros, y Sales Filho, 2014), es el espacio que el turismo ha buscado tradicionalmente y sigue buscando con preferencia (Rodríguez, 1994); es, incluso, el rostro de un territorio. Ha tenido gran importancia en las políticas globales y nacionales para el desarrollo del turismo (Aguilar, Palafox y Anaya, 2015) y es un activo valioso para los proyectos turísticos a gran escala (Botero et al., 2013; Iglesias et al., 2018; Semeoshenkova y Newton, 2015; Sytnik y Stecchi, 2015).

Las playas con alto valor ecológico y paisajístico son el recurso más importante (Iglesias et al., 2018; Roig-Munar et al., 2013), se encuentran entre los principales factores responsables del atractivo de los destinos turísticos (Soares, Medeiros y Sales Filho, 2014). La belleza escénica, la costa, la playa, el mar, y la naturaleza adquieren gran importancia para el desarrollo de destinos (Malvárez García, Gonzalo Pollard y Domínguez Rodríguez, 2009; Garay y Cànoves, 2011; Iglesias et al., 2018). La composición escénica de los elementos naturales de los paisajes son la materia prima del turismo: el agua, la vegetación, la geomorfología y la fauna, además de la estacionalidad y los episodios climáticos constituyen el recurso de mayor atracción e importancia (Dos Santos, 2011).

El paisaje representa un importante atractivo para el turismo, y en el caso de los destinos litorales constituye el recurso más importante para el desarrollo de la oferta turística. La imagen de un destino turístico, esencialmente asociada a su paisaje, surge como factor decisivo sobre la motivación y la preferencia de la demanda (Dos Santos, 2011; Soares et al., 2014), siendo la belleza paisajística el elemento del entorno que más influye en la opción por un destino vacacional (Giné, 2015). La calidad visual de los paisajes ha sido un factor de motivación turística, por ello su conservación debe ser primordial pues los turistas muestran cierta sensibilidad a la calidad estética de los paisajes, generando una dependencia entre su calidad ambiental y la derrama económica hacia el turismo (Torruco y González, 2012). 


\subsection{El paisaje en la conformación de destinos turísticos litorales}

En la historia del turismo moderno los destinos ubicados en los litorales, sustentados en el sol y la playa, han constituido gran parte de la oferta turística (Castillo y Villar, 2014; Iglesias, Anfuso, Uterga, Arenas, y Williams, 2018; Lozoya, Sardá, y Jiménez, 2014). En México, así como en otros países, desde la década de los años setenta se impulsó el turismo como vía para el desarrollo regional (Castillo y Villar, 2014; Dávila, 2014; Benavides, 2015). Los sitios con un elevado valor ambiental y paisajístico, y con una localización geográfica estratégica para la captación de mercados internacionales, fueron elegidos para el desarrollo de destinos turísticos a gran escala, favoreciendo la participación de inversiones estatales, particulares o mixtas (Fonatur, s.f.; Castillo y Villar, 2014).

Para el desarrollo de estos destinos, la política económica estableció sitios de interés de acuerdo con criterios comerciales (Millán, 2012; Castillo y Villar, 2014; Aguilar, Palafox y Anaya, 2015), pero considerando la riqueza biológica y estética de los sitios (Dávila, 2014; Demajorovic et al., 2011). El sector turismo se enfocó en la creación y desarrollo de enclaves, con el objetivo de concentrar servicios turísticos en lugares con especial potencial turístico, basado en sus recursos naturales y paisajísticos, y caracterizados por un desarrollo importante de infraestructura (Semeoshenkova y Newton, 2015; Iglesias et al., 2018), atraídos por los atractivos paisajísticos de las costas (Demajorovic et al., 2011), y considerando su calidad estética (Santos y Vilar, 2013).

Los enclaves de sol y playa han sido pensados como sitios de recreación turística aprovechando la belleza de sus paisajes, sus playas vírgenes, sus áreas selváticas y la abundancia de su naturaleza tropical (Talledos, 2012). Para el desarrollo del turismo litoral se ha facilitado el cambio de uso de suelo en sitios de alto valor ecológico y paisajístico (Palafox et al., 2011), y se han replicado patrones arquitectónicos favoreciendo que el paisaje tienda a replicarse en la mayor parte de los destinos, al seguir similares patrones arquitectónicos y estéticos, y al contar con infraestructura, equipamiento y servicios similares (ver Figura 1), modificando el paisaje y poniendo en riesgo, en algunos casos, su conservación (Barreto y Rodrigues, 2012; Nogué, 1989; Rico-Amoros, Sauri, Olcina-Cantos, y Vera-Rebollo, 2013; Torruco y González, 2012). 
Figura 1. Diferentes Enclaves Turísticos Mexicanos
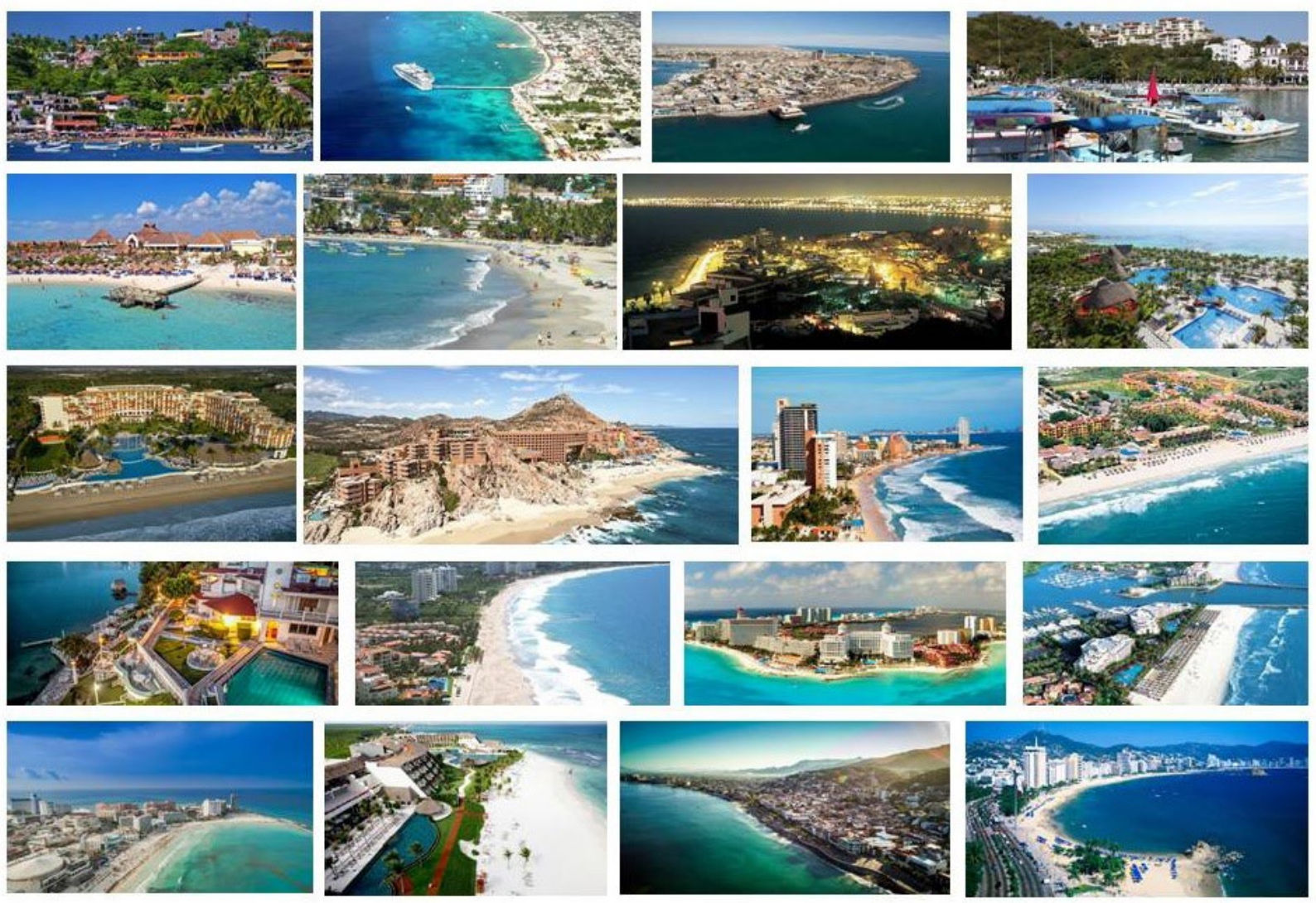

Fuente: Google.

\section{METODOLOGÍA}

Se realizó una investigación teórica, descriptiva y observacional, a través de los métodos descriptivo correlacional y teórico experimental. El método descriptivo correlacional, a partir de la observación directa no participante, indirecta en fuentes primarias y secundarias, y controlada a través de un estudio de caso, permitió reconocer la importancia del paisaje en la conformación, desarrollo y consolidación de Cancún. Mientras que el método teórico experimental permitió determinar el impacto paisajístico en el destino.

\subsection{Revisión Bibliográfica y Hemerográfica}

Durante la revisión bibliográfica y hemerográfica se analizaron artículos científicos, reportes de investigación, reportes gubernamentales, libros, proyectos, tesis, memorias de congresos, cartografías, publicaciones, notas periodísticas, videos, fotografías, material promocional, entre otros, que abordaran la creación y desarrollo del Centro Integralmente Planeado Cancún, a lo largo de más de 40 años. Mediante este análisis fue posible comprender el modelo de desarrollo turístico que se apropia del paisaje como un recurso susceptible de ser utilizado para la promoción y oferta de esta actividad económica, así como la generación de impactos sobre el paisaje. 


\subsection{Trabajo de campo}

A lo largo de la investigación se realizaron cinco visitas de campo. La primera en septiembre de 2015, la segunda en agosto de 2017, la tercera en noviembre de 2017, la cuarta en enero de 2018 y la quinta en julio de 2018. La finalidad de las visitas de campo fue conocer y estudiar el paisaje turístico litoral de Cancún. Durante las visitas fue posible conocer las características del paisaje, realizar un inventario turístico, aplicar encuestas, y evaluar la calidad y la fragilidad visual del paisaje. Para la evaluación de la apropiación del paisaje se aplicó una encuesta en algunos de los sitios más emblemáticos de la zona turística. La finalidad del instrumento fue identificar el tipo de apropiación paisajística por parte del visitante. Los resultados del trabajo de campo contribuyeron a la caracterización y la descripción del paisaje del destino.

\subsection{Contextualización del sitio de estudio.}

Derivado de la revisión de literatura, del trabajo de campo y del diseño de un sistema de indicadores, fue posible contextualizar a Cancún y describir el paisaje turístico litoral. Primeramente se definió el sitio de estudio, es decir, su delimitación geográfica, para posteriormente describir sus aspectos físicos y biológicos, y finalmente la relevancia del turismo, desde distintas variables. Se trató de explicar cómo ha sido utilizado el paisaje para la creación del centro turístico y como su creación y desarrollo ha incidido, mayormente de manera negativa, sobre el paisaje. Así se analizó la participación del turismo en la generación de impactos ecológicos y paisajísticos en Cancún.

\subsection{Evaluación del paisaje de Cancún}

Para la evaluación del paisaje se definieron la cuenca visual y las unidades del paisaje, y se tomó como referencia el modelo indirecto del Bureau of Land Management (1980 en Paredes, 2013) y la técnica basada en la metodología de Yeomans (1986 en Paredes, 2013). Para la evaluación del impacto se utilizó la matriz de Causa Efecto y el método de valoración de impactos de Gómez Orea (2002). A partir del sistema de indicadores y del trabajo de campo fue posible realizar las evaluaciones de calidad y fragilidad visual del paisaje, así como del impacto del turismo en Cancún.

\section{RESULTADOS}

\subsection{Creación y Desarrollo del Centro Integralmente Planeado Cancún}

En 1953 José Lima plantea el desarrollo turístico en Cancún bajo el nombre de zona turquesa y en junio de 1962 plantea la necesidad de implementar el turismo en la zona, principalmente por la generación de empleos que representaría. En 1968 construye una casa de verano, la Casa Maya, y en 1970 se decide finalmente iniciar el proyecto, el cual debía ofrecer no solamente mar y sol, sino la propia cultura maya; así sus primeras construcciones fueron diseñadas bajo el concepto de paisaje autóctono, mediante el uso de palapas (Universidad del Caribe, 2011c). 
Cancún se edificó prácticamente de la nada. Fue pensado como un sitio de recreación turística para personas de alto nivel de ingresos, aprovechando la belleza del paisaje, sus playas vírgenes, sus áreas selváticas y la baja densidad de población, y resultó una experiencia exitosa, pues en menos de tres décadas logró convertirse en el destino más importante del turismo internacional en México y en el principal centro de captación de divisas del sector (Oehmichen, 2010: 25). Se concibió como un lugar integrado por una zona hotelera y una zona urbana, que albergaría a los mandos medios de los hoteles, de la burocracia y de los servicios, constituyendo así una zona habitacional y comercial (Hiernaux Nicolas, 1999 en Oehmichen, 2010). En las figuras 2, 3 y 4 se muestran algunas imágenes del desarrollo del centro turístico.

Dentro del alojamiento se consideró construir hoteles con categoría de 1 a 3 estrellas con frente al mar y al Boulevard Kukulkán, villas, condominios y lotes residenciales en tres zonas, a lo largo de la primera etapa, y en los terrenos aledaños a lo que sería el campo de golf. Se planeó utilizar espacios de la zona de manglar, con frente a la Laguna de Nichupté, para construir hoteles de primera categoría. El equipamiento turístico consideró la construcción de un campo de golf, un centro de convenciones, clubes náuticos y el rescate de las zonas arqueológicas Ruinas del Rey y San Miguelito.

Se previó conservar los espacios de alto valor ecológico (zonas de manglar, sabana, palmar y selva tropical) en su estado natural, a fin de mantener el equilibrio ecológico. En la zona urbana se consideraron siete componentes: habitación, equipamiento turístico, equipamiento urbano, espacios abiertos, industria, vialidad y reserva (Fonatur, 1982). El Plan Maestro de Cancún consideró un horizonte de planeación de 25 años, estructurándose en tres etapas: de 1975 a 1981, de 1982 a 2000, y la tercera a partir del 2001. Las etapas de desarrollo de los planes y programas de Cancún desde 1970 muestran una clara tendencia a ubicar la zona urbana en los límites de la selva y los manglares. 
Figura 2. Fotografías del desarrollo del turismo durante la primera etapa

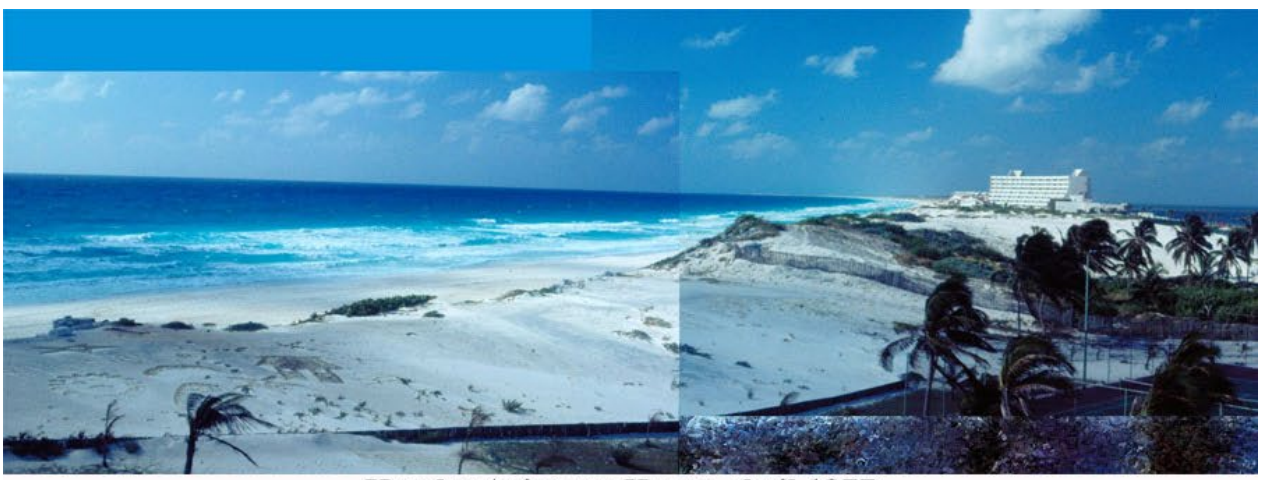

Hoteles Aristos y Hyatt, abril 1977

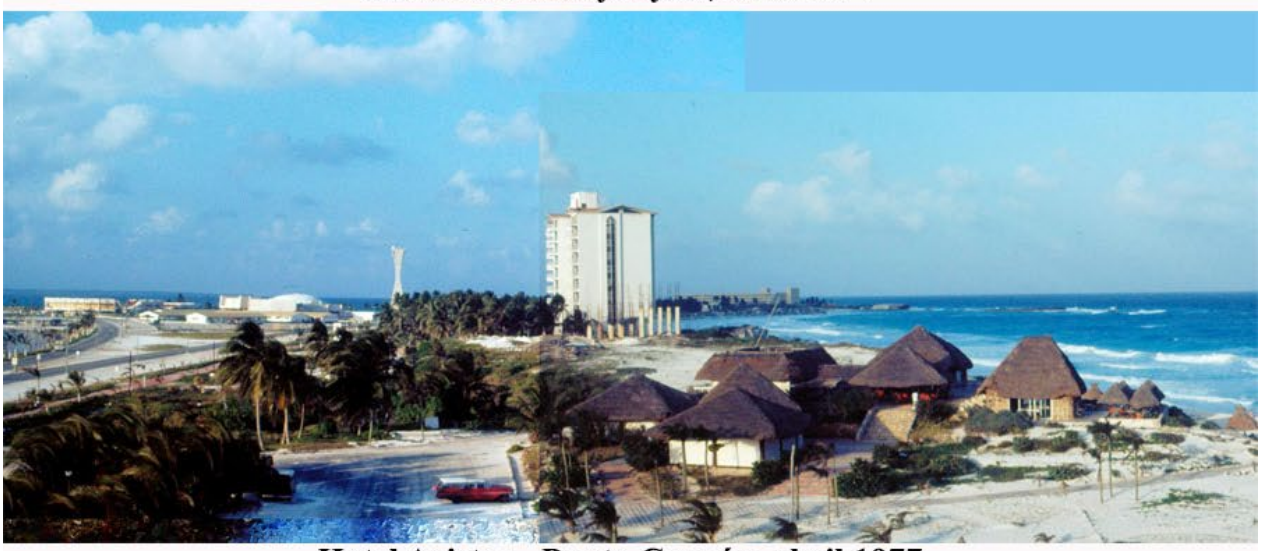

Hotel Aristos - Punta Cancún, abril 1977

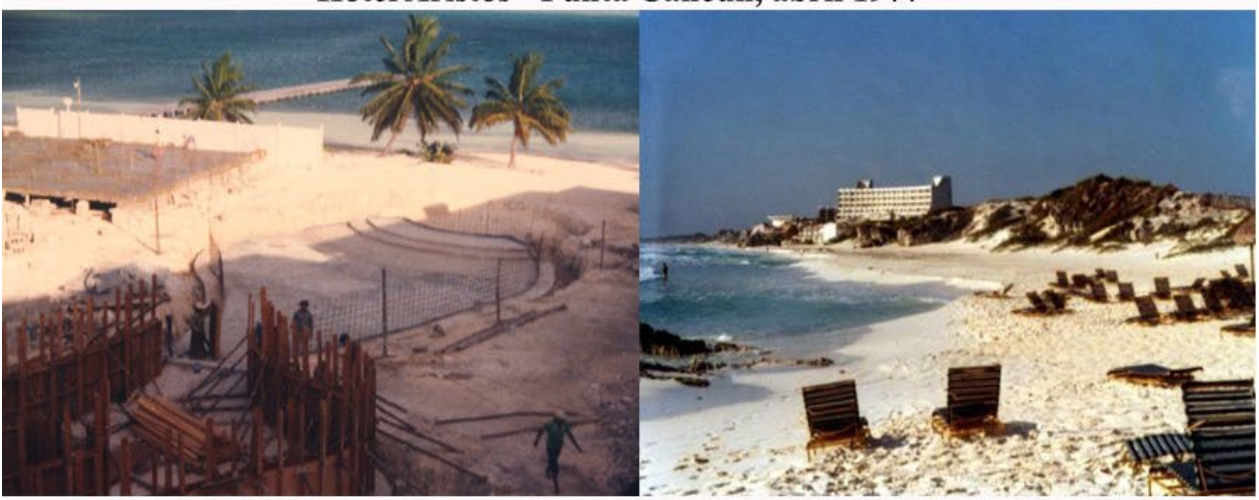

Construcción Hotel Royal Resorts, 1977

Playa Chaac Mool, 1978

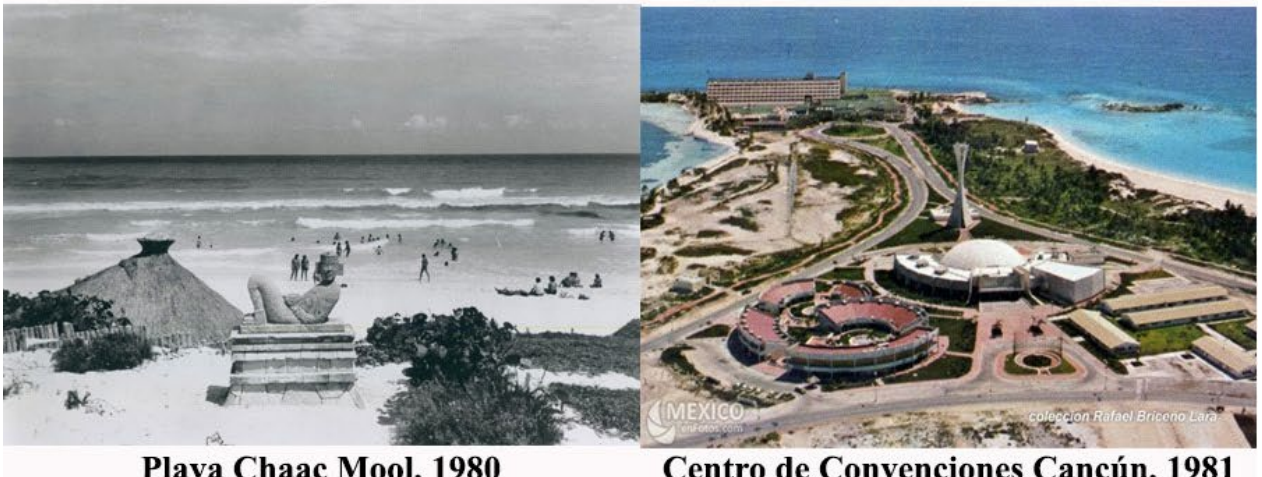

Fuente: Uluapa Sr, 2011. 
Figura 3. Fotografías del desarrollo del turismo durante la segunda etapa

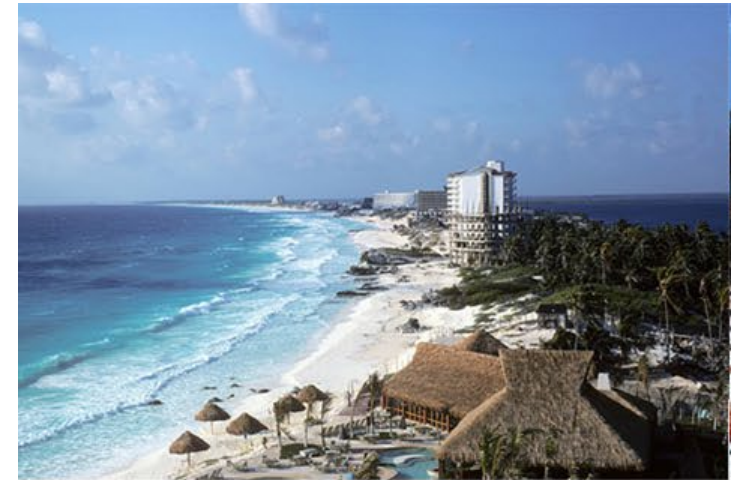

Hotel Cristal, enero 1982

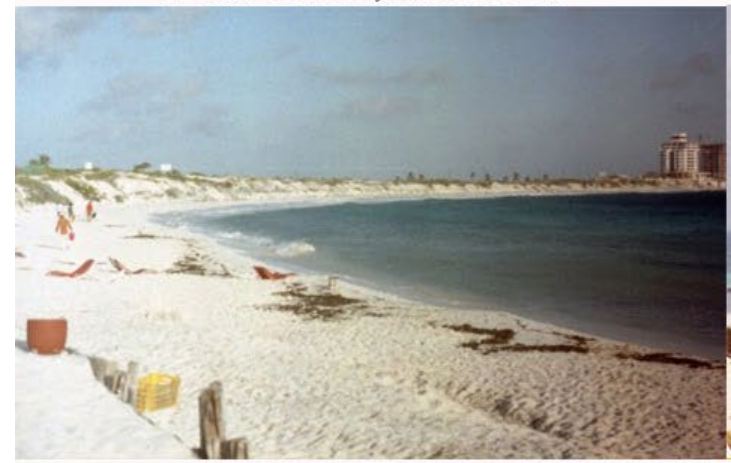

Punta Nizuc, 1983

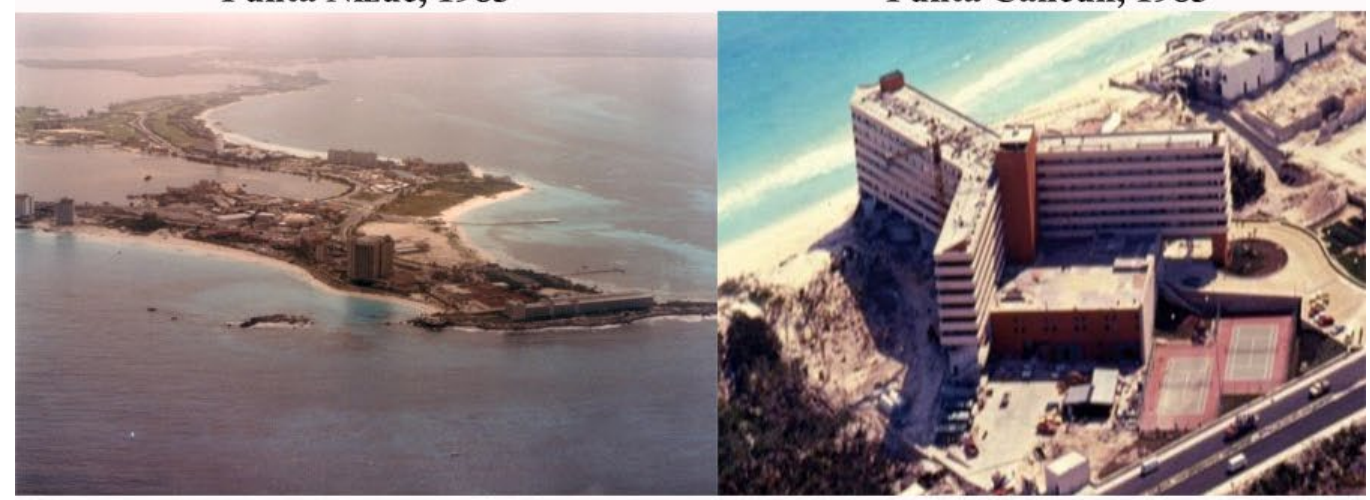

Vista Panorámica de Punta Cancún, 1985

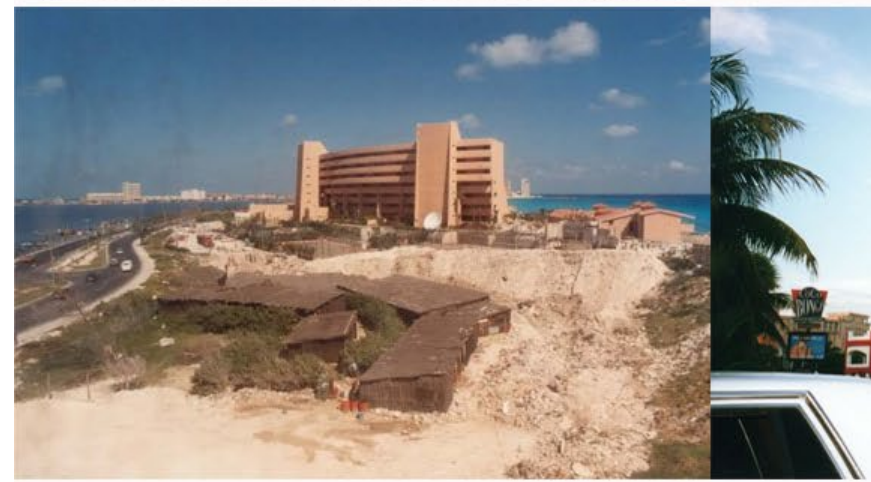

Hotel Hyatt, 1989

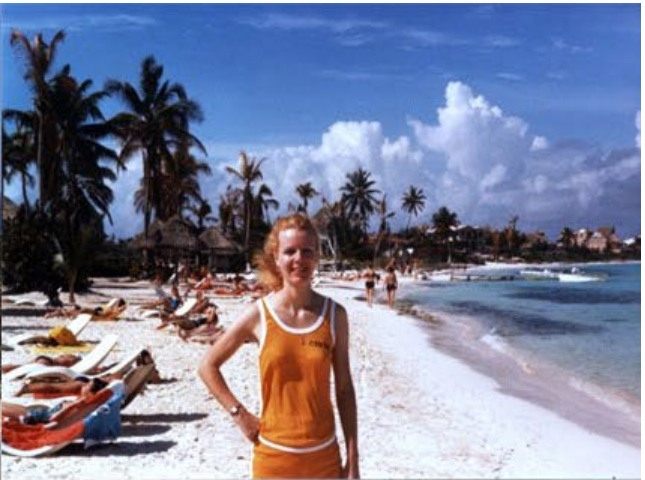

Playa del Hotel Presidente, 1982

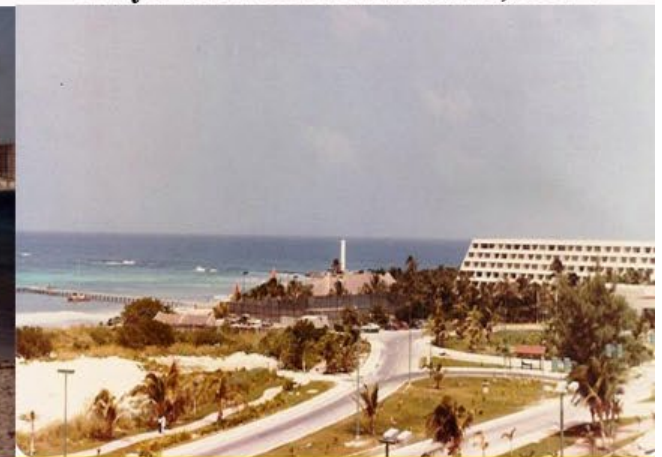

Punta Cancún, 1983

Hotel Caribbean Village 1988

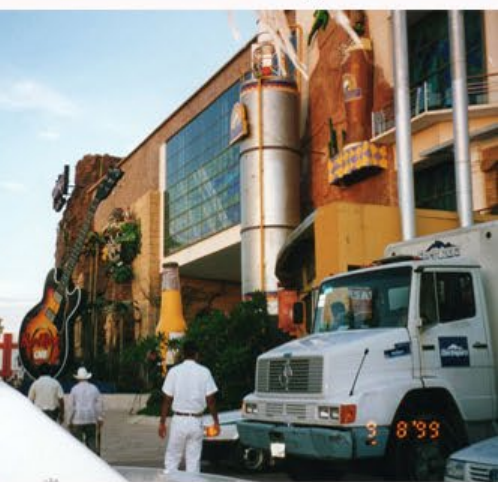

Plaza Forum, 1999

Fuente: Uluapa Sr, 2011. 
Figura 4. Fotografías del desarrollo del turismo durante la tercera etapa

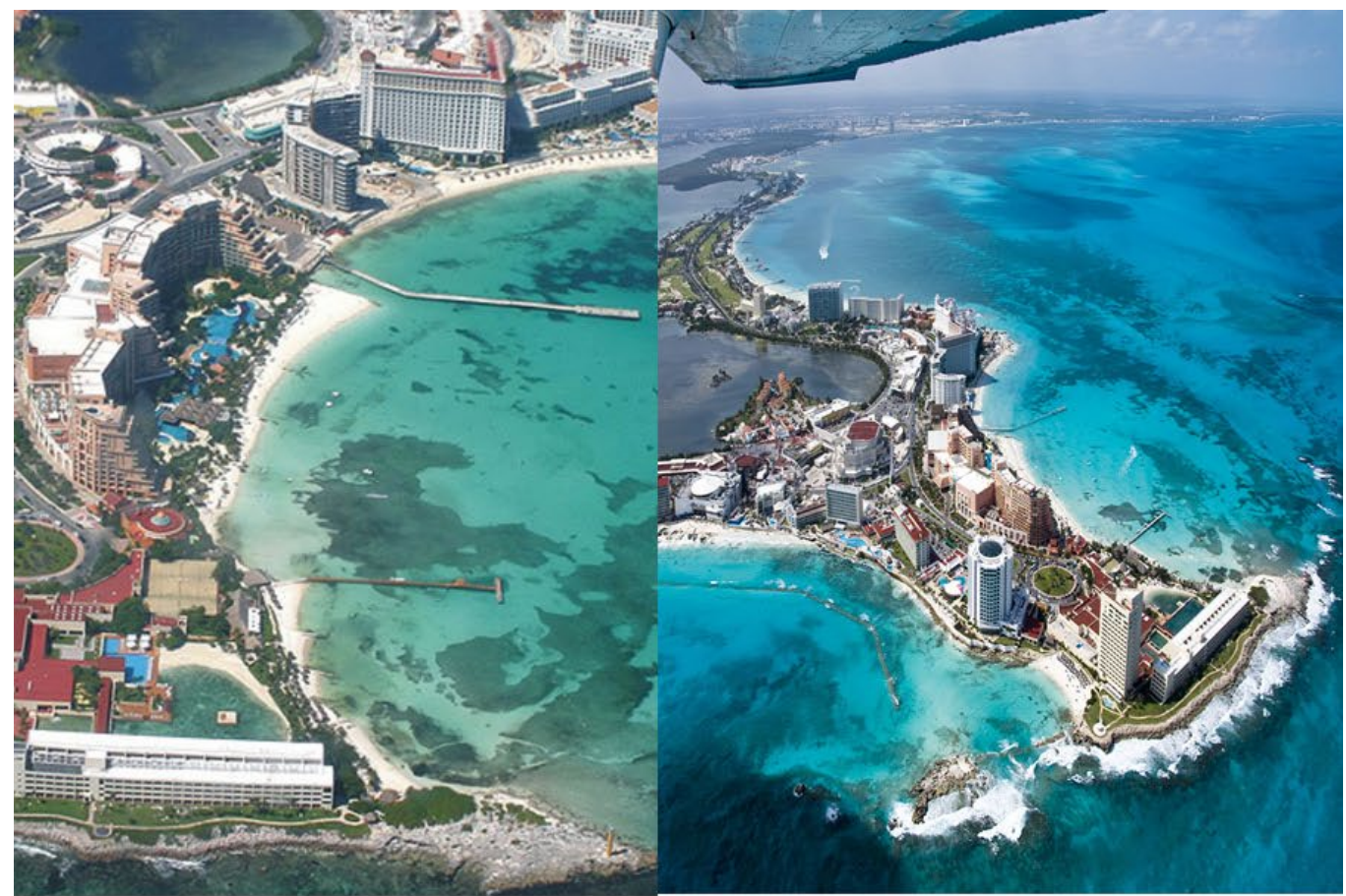

Playa Caracol, 2006

Vista panorámica de Punta Cancún, 2007

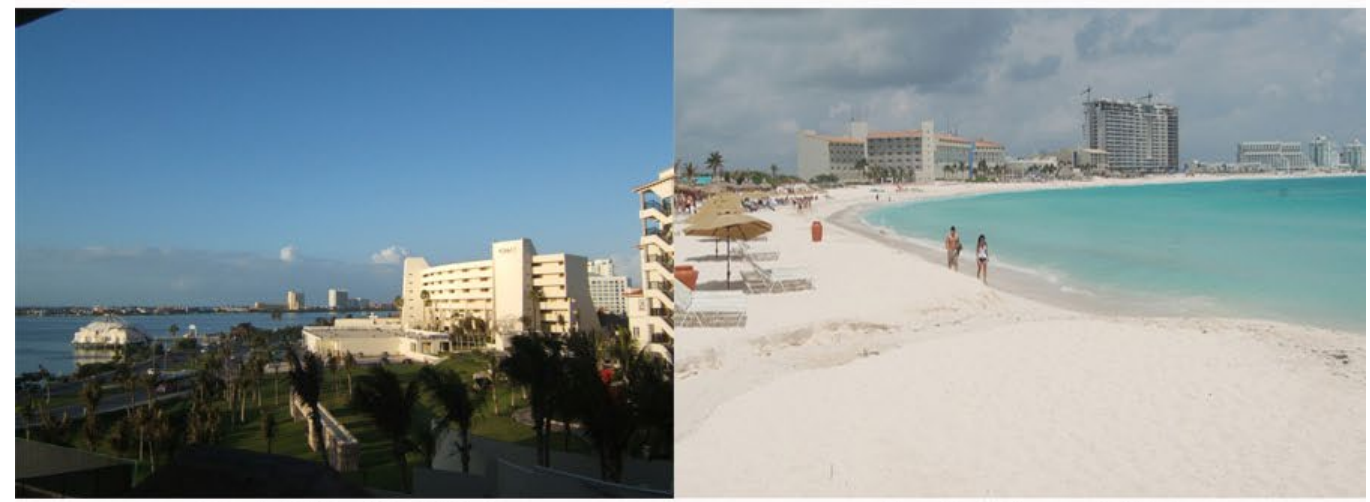

Hotel Hyatt, 2007

Punta Nizuc, 2007

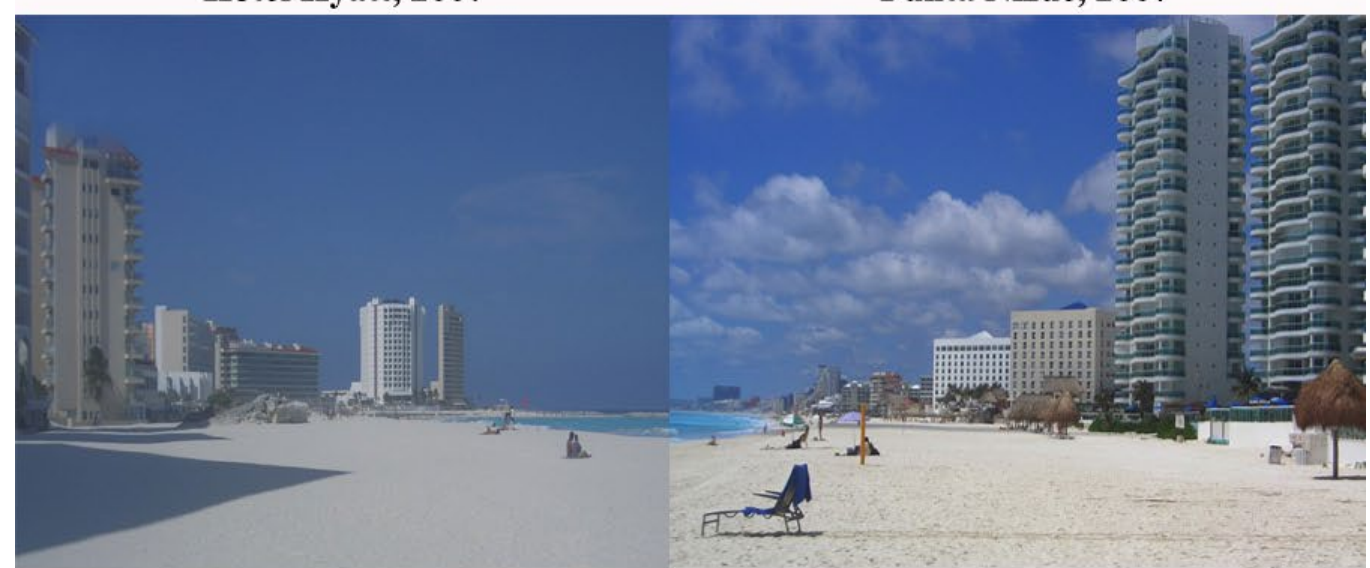

Punta Cancún, 2010

Playa Chaac Mool, 2010

Fuente: Uluapa Sr, 2011. 


\subsection{Evaluación del Paisaje}

Para la evaluación del paisaje se definieron la cuenca visual y las unidades del paisaje (ver Figura 5). El paisaje turístico litoral de Cancún es un territorio altamente antropizado que conserva grandes espacios con características naturales y donde existen elementos de gran singularidad, alto valor perceptual y alto valor escénico. Si bien al interior de las Unidades de Paisaje existe poca variedad cromática, en su conjunto se considera que la riqueza cromática de la Cuenca Visual es considerable y que el paisaje intrínseco es rico. Sin embargo, la visibilidad es muy limitada en algunas zonas, debido a la morfología del territorio con poco relieve y a la saturación y altura de la infraestructura hotelera, siendo esta misma quien ofrece los principales puntos de observación panorámica del paisaje, aunque con vistas parciales, ya sea hacia la laguna y el manglar o bien hacia el mar y la playa.

Figura 5. Cuenca visual de Cancún

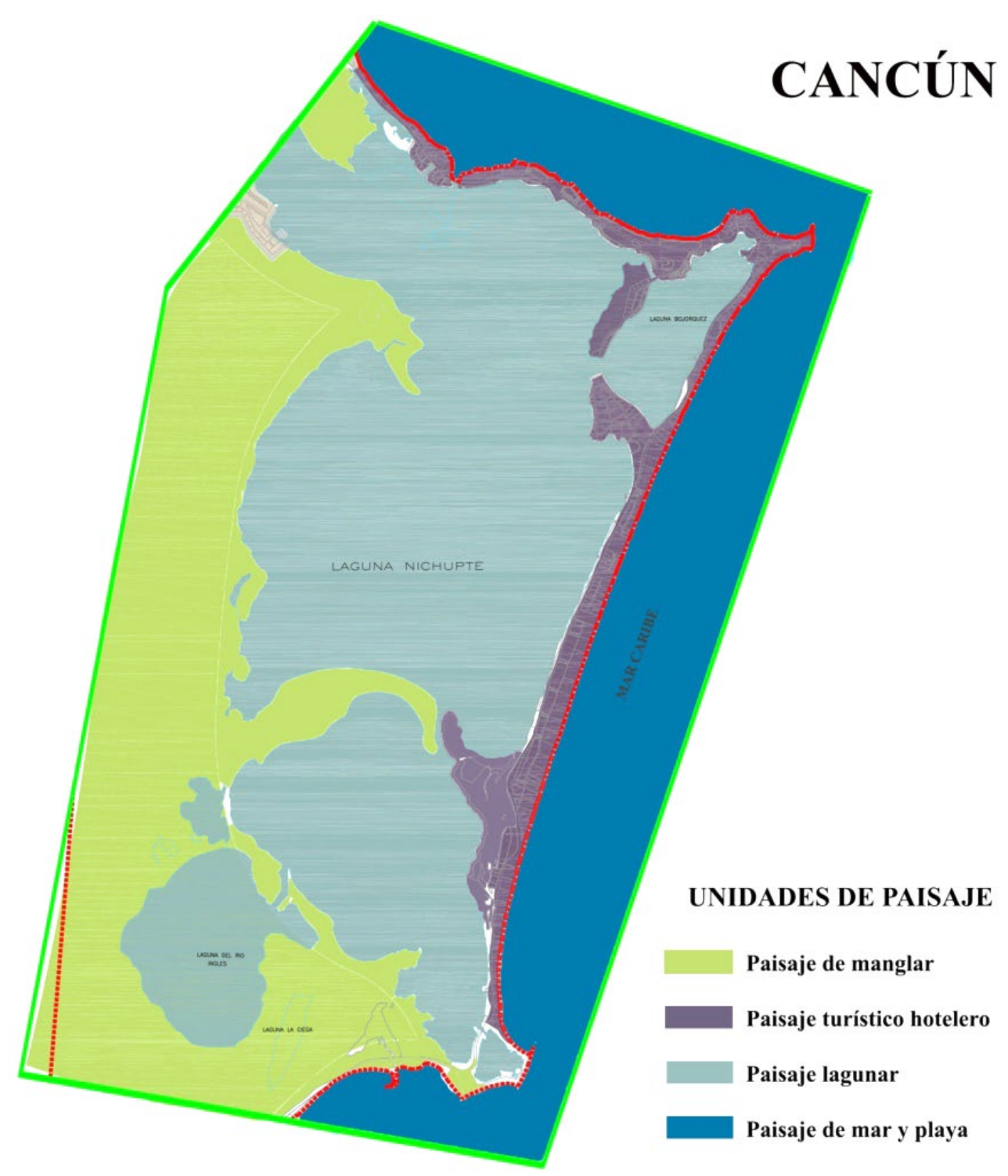

Fuente: Elaboración propia. 
Se trata de un paisaje con áreas de alta calidad, con rasgos singulares y sobresalientes, debido a la variedad de la vegetación y los cuerpos de agua presentes que le confieren variabilidad cromática, fondo escénico y singularidad. Y, pese a que se trata de un paisaje con modificaciones antropogénicas intensas y extensas, que reducen la visibilidad, aún conserva una alta calidad. Respecto de la capacidad de absorción visual (CAV) del paisaje se considera moderada, lo que significa que presenta cierto grado de vulnerabilidad ante las modificaciones del entorno.

\subsection{Impacto del turismo sobre el paisaje de Cancún}

Se observó que la incidencia de impactos con mayor ponderación se presentaron durante las primeras dos etapas (1970-2001), situación que resulta lógica al considerar que durante estas etapas se alcanzó el mayor grado de desarrollo de infraestructura y equipamiento turístico en el destino y que sus tendencias de crecimiento rebasaron las proyecciones de Fonatur, dándose un crecimiento superior al esperado, ocasionando el sobre uso de recursos, principalmente suelo y agua, y que la magnitud de la urbanización turística en un período tan corto modificó de forma acelerada la fisonomía del paisaje, incidiendo de forma negativa en su calidad, al reducir la accesibilidad visual.

Es importante señalar que, pese a las grandes transformaciones que ha sufrido el paisaje litoral de Cancún, en sus diferentes elementos y componentes, ninguno de los impactos se consideró significativo o relevante, lo cual se explica por la extensión de la cuenca visual. Cabe destacar que uno de los factores que contribuyó a que la magnitud de los impactos se redujera un poco en el tiempo, fue que en la tercera etapa de desarrollo turístico las tendencias de crecimiento se dieron hacia el otro extremo del manglar, y aunque la construcción de infraestructura turístico hotelera continuó sobre la zona turística, su crecimiento fue mucho más lento y menos expansivo que en las dos primeras etapas. Además, derivado de las grandes transformaciones e impactos negativos por sobreuso de recursos naturales, durante la tercera etapa se han implementado medidas correctivas y preventivas, pero sobretodo de mitigación.

\section{DISCUSIÓN}

La decisión de construir un centro integralmente planeado, y con ello un nuevo destino turístico en Cancún, se basó en su paisaje natural y la belleza de sus playas. Para 1970 el territorio hoy ocupado por el centro turístico estaba inhabitado, abundaba el manglar y sus playas eran vírgenes. Para la construcción de infraestructura turística se consideró utilizar materiales de la región para construir palapas; este tipo de edificación se utilizó en el aeropuerto y en los primeros establecimientos de hospedaje y de alimentos, destacando playa Chaac Mool.

De acuerdo con el plan Maestro de Fonatur se previó el desarrollo del centro turístico a partir de tres etapas, lo que implicaba un crecimiento de infraestructura hotelera de manera paulatina. En la década de los 70 se observó un crecimiento hotelero relativamente 
lento y una ocupación del territorio de intensidad media, pues se construyeron complejos hoteleros de gran escala, como el Club Med en Punta Nizuc, el cual para 1975 contaba ya con una gran cantidad de edificios para habitaciones y servicios, así como canchas deportivas (ver Figura 6).

Y, para 1977, en Punta Cancún se encontraban los hoteles Aristos y Hyatt, el centro de convenciones y muchas otras edificaciones (ver Figura 2, fotografías de abril) que muestran, en dos diferentes tomas, un paisaje natural poco intervenido, pero también un paisaje altamente antropizado, coexistiendo con las palapas y mostrando algunos vestigios de la vegetación, principalmente de dunas. La zona de manglar había cedido su lugar al ya entonces Boulevard Kukulkan y las distintas edificaciones turísticas. En la Figura 7 se presenta una fotografía aérea tomada en mayo de 1978 dónde se observa, al norte, el desarrollo turístico hacia Punta Cancún y, en el sur, el complejo hotelero de Club Med en Punta Nizuc. El paisaje natural del sitio había sido altamente transformado en la zona norte.

Figura 6. Instalaciones de Club Med en 1975

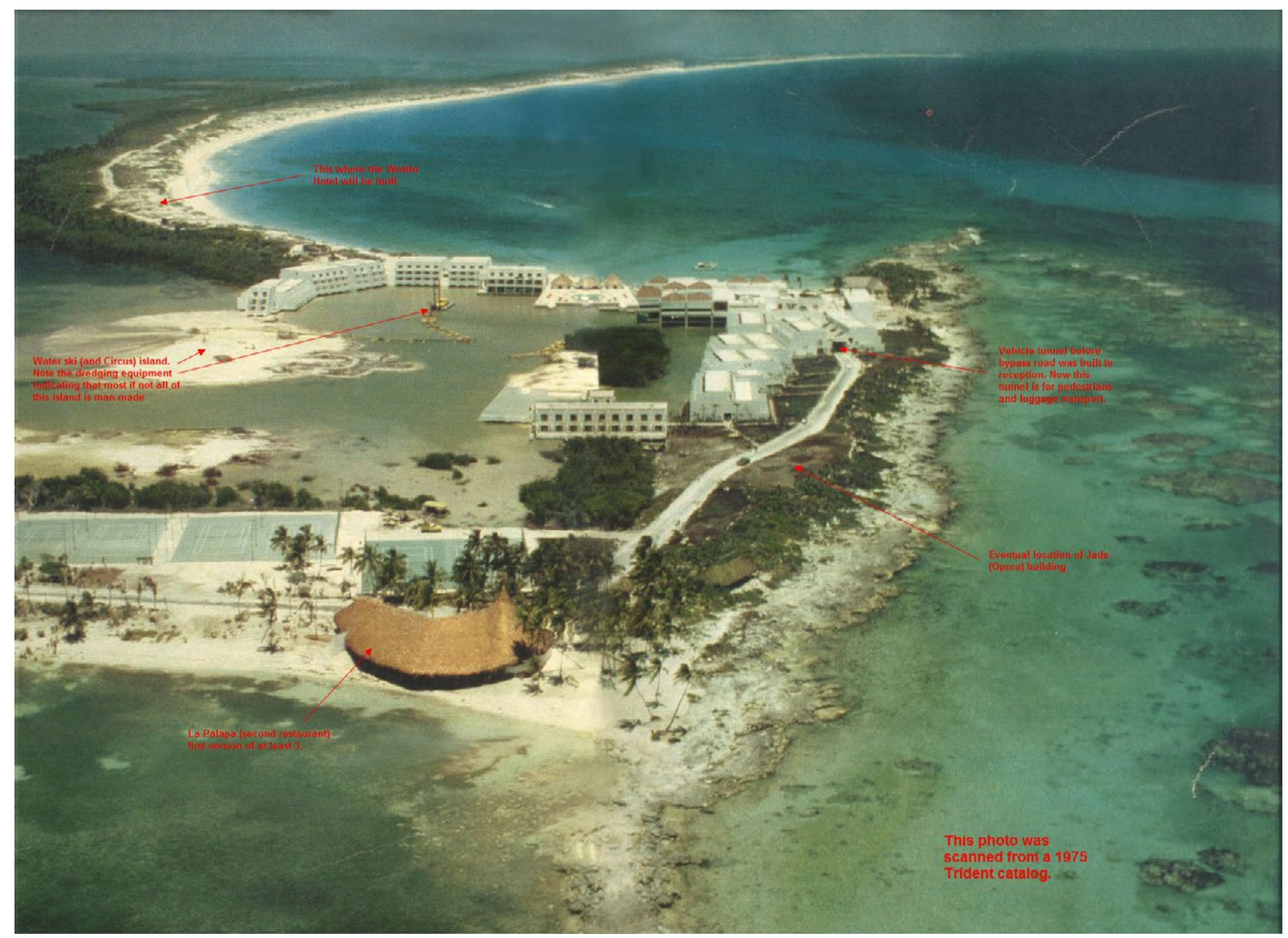

Fuente: Uluapa Sr, 2011. 
Figura 7. Fotografía aérea Cancún en mayo de 1978

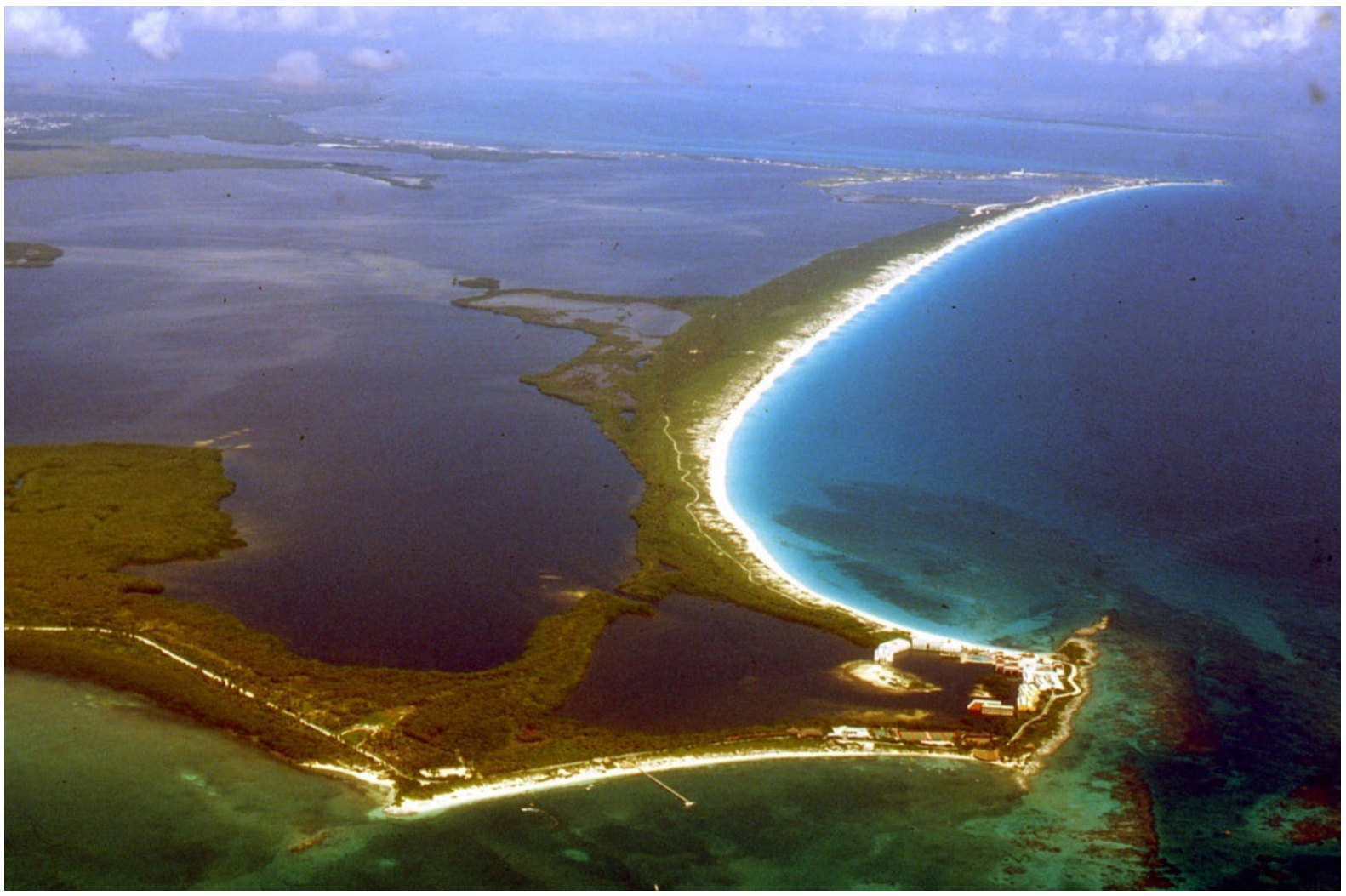

Fuente: Uluapa Sr, 2011.

Y en los siguientes años el desarrollo de infraestructura turístico-hotelera continuaría hacia el sur hasta Punta Nizuc (ver Figura 8 y Figura 9), modificando totalmente el paisaje natural del territorio, dando paso a un nuevo paisaje, uno antropizado, replicando los destinos turísticos litorales de otras partes del mundo, caracterizados por una alta concentración de infraestructura hotelera de alto rango con cadenas hoteleras internacionales. No obstante, esta importante transformación del paisaje, si bien ha traído consigo una serie de impactos ecológicos, territoriales y paisajísticos, ha concedido a este centro turístico una fisonomía muy particular y ha creado un nuevo paisaje con una peculiar característica que, aunque replica el diseño de otros tantos enclaves turísticos, llega a ser un tanto distinto por la riqueza biológica que aún existe en el sitio, y que le confiere un plus como destino turístico. La base de su configuración geomorfológica, en forma de "7", los manglares, el sistema lagunar, la playa y el mar le dan una fisonomía muy particular que hacen del paisaje de Cancún un paisaje inconfundible. 
Figura 8. Fotografía aérea de Cancún en agosto de 1988

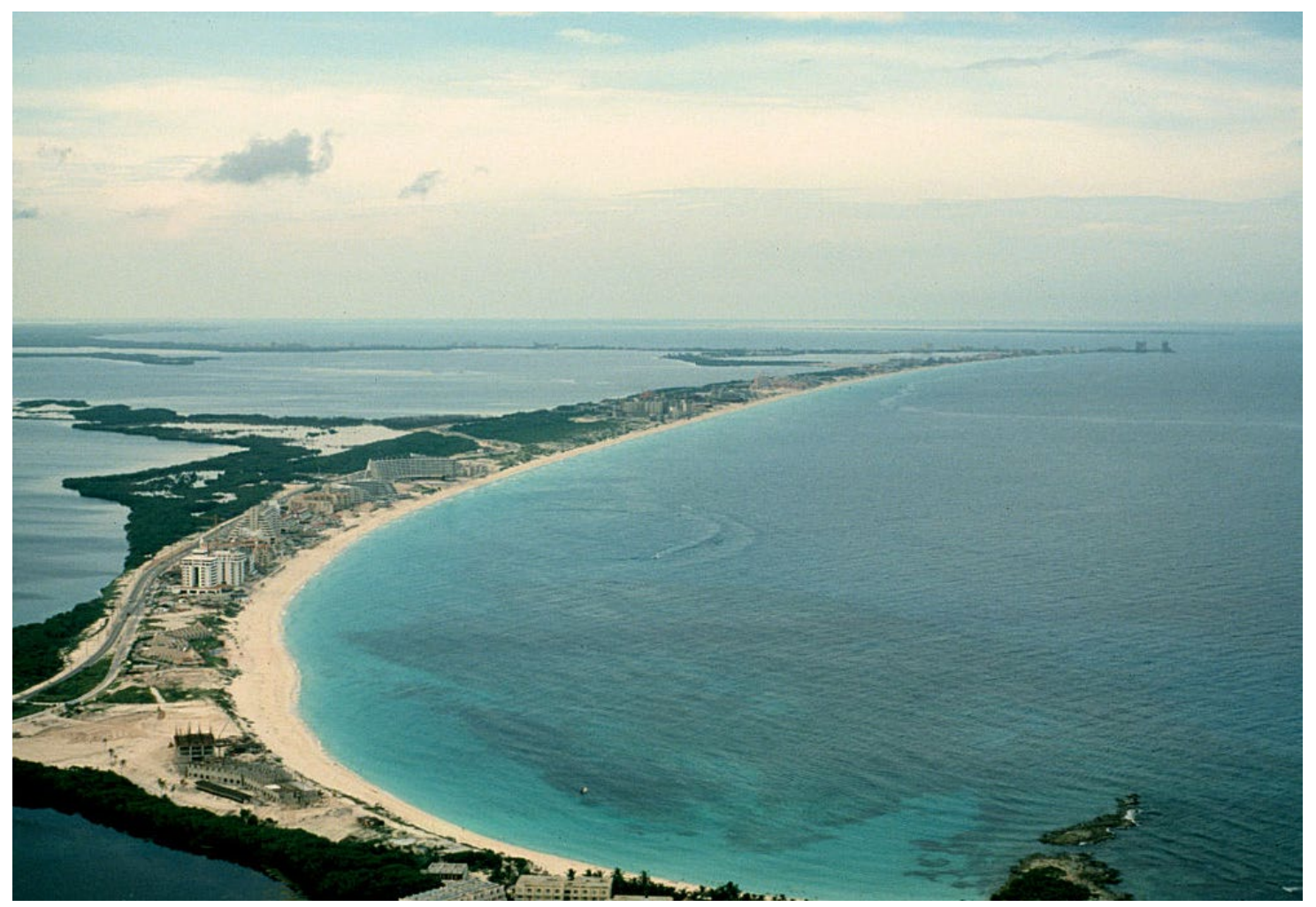

Fuente: Fotografía tomada por delange, panoramio en Uluapa Sr, 2011.

Figura 9. Fotografía aérea de Cancún en 2007

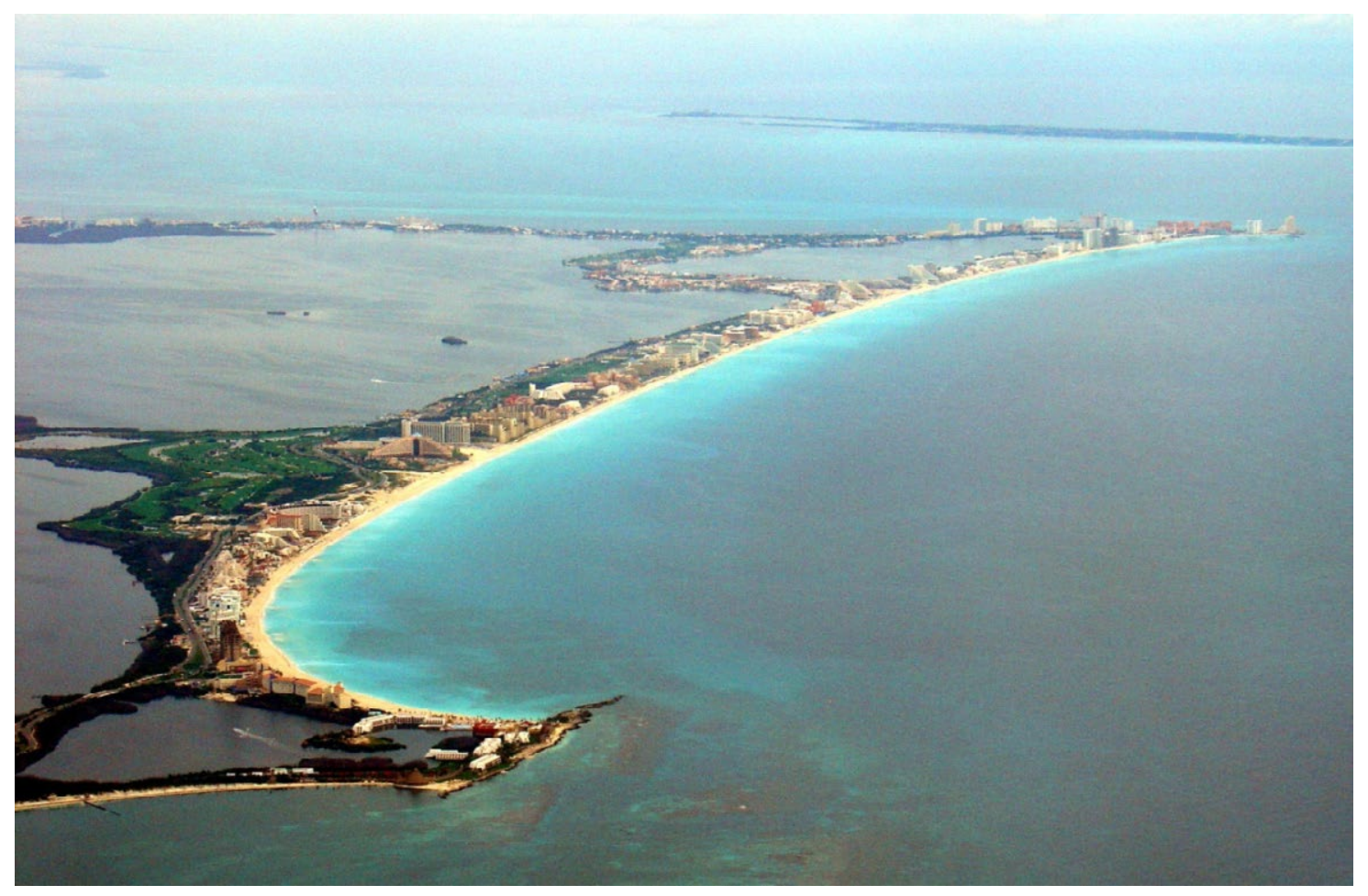

Fuente: Fotografía tomada por ruedi_w, panoramio en Uluapa Sr, 2011. 
En relación con la calidad visual del paisaje, al asignársele valor comercial se ha modificado fuertemente su fisonomía original. Cabe señalar que la contaminación e intrusión visual alcanzaron valores importantes, aunque no se consideran significativos, en relación con la extensión de la cuenca visual; dado que la cuenca visual es muy extensa, y los puntos de observación panorámica son muchos, incluidos los aéreos, aún es posible tener panorámicas singulares, espectaculares y de muy alta calidad. Las tendencias de crecimiento actuales seguirán impactando negativamente sobre los recursos paisajísticos. Dicho impacto estará sujeto a la calidad visual del paisaje, a las medidas de mitigación y adaptación ante la incidencia de fenómenos hidrometeorológicos, a la conservación de los ecosistemas y al establecimiento de políticas de ordenamiento territorial acordes con la conservación del paisaje. Se destaca el hecho de que se le ha asignado un valor económico muy importante al paisaje, pero se ha dejado de lado la importancia de mantener su calidad, la cual ha ido disminuyendo al paso del tiempo y del aumento de infraestructura y equipamiento turísticos. Finalmente, es importante mencionar que, a la fecha, no existen instrumentos de gestión del paisaje.

\section{CONCLUSIÓN}

El paisaje es uno de los atractivos y recursos más importantes para el desarrollo del turismo litoral. Éste ha constituido el valor principal de destinos como Cancún. Sin embargo, el desarrollo de la actividad turística conlleva la transformación del paisaje, transformación que puede darse de forma paulatina, aunque en la mayoría de los casos ocurre en periodos cortos, y en tan solo un par de décadas un paisaje natural, completamente virgen, puede ser totalmente transformado y antropizado, situación que puede poner en riesgo la continuidad del propio recurso y del turismo mismo.

No obstante, es posible que un territorio, cuyos atributos paisajísticos que fueron los detonantes para el desarrollo del turismo, aun altamente modificado siga ofreciendo paisajes turísticamente atractivos, como es el caso de Cancún. Sin embargo, no debe olvidarse que los recursos ecológicos constituyen gran parte de los recursos paisajísticos y que su calidad, deterioro y desaparición pueden impactar fuertemente en la calidad de los paisajes turísticos y, por ende, en la derrama económica del turismo.

Por ello, es importante analizar cómo el desarrollo de un destino puede llevar a la transformación del territorio en periodos tan cortos y como a pesar de que éste sigue conservando de alguna manera su valor para el turismo, si continúa con las tendencias de expansión, como en el caso de Cancún, en el corto o en el mediano plazo, las transformaciones del paisaje serán tan profundas que no habrá ya paisajes de calidad o excepcionalidad para ser ofertados por el turismo. Así, este documento pretende ser una alerta en el manejo sustentable del turismo, considerando al paisaje como un elemento clave que puede ser explotado turísticamente, pero que también debe protegerse para asegurar su continuidad y la del turismo en un determinado territorio. 


\section{REFERENCIAS BIBLIOGRÁFICAS}

Aguilar, A., Palafox, A., y Anaya, J. S. (2015). El turismo y la transformación del paisaje natural. Noésis Revista de Ciencias Sociales y Humanidades, 24 (número especial), 19-30.

Barreto, I., y Rodrigues, E. (2012). Paisaje y Medio Ambiente. Las transformaciones ocasionadas por el turismo de segundas residencias en las playas de Jacumã, Carapibus y Tabatinga (Conde/PB, Brasil). Estudios y Perspectivas yn Turismo, 21, 141-158.

Benavides, M. (2015). Un enclave turístico y el costo social de su proceso de expansión territorial. URBS. Revista de Estudios Urbanos y Ciencias Sociales, 5(2), 95-110.

Botero, C., Anfuso, G., Williams, A., y Palacios, A. (2013). Perception of coastal scenery along the Caribbean littoral of Colombia. Journal of Coastal Research, 2(65), 1733-1738.

Bottero, M. (2011). Indicators Assessment Systems. In C. Cassatella y A. Peano (Eds.), Ladscape Indicators. Assessing and Monitoring Landscape Quality (pp. 15-29). Springer.

Cancer, L. (1994). Aproximación crítica a las teorías más representativas del paisaje. GEOGRAPHICALIA, 31, 17-30.

Castillo, O., y Villar, A. (2014). El estado y la política de los polos turísticos de desarrollo: el caso de Cancún, México. Revista de Urbanismo, Departamento de Urbanismo, Universidad de Chile, 31, 18-36.

Consejo de Europa. (2000). Convenio Europeo del Paisaje. Convenio Europeo del Paisaje. Florencia.

Contreras, C. (2005). Pensar el paisaje. Explorando un concepto geográfico. Trayectorias, Revista de Ciencias Sociales de La Universidad Autónoma de Nuevo León, 7(17), 57-69.

Covarrubias, F. (2015). El paisaje: arte, contemplación y teorización científica, ms. México, D.F., México: Instituto Politécnico Nacional.

Dávila, A. (2014). Centros integralmente planeados (CIPS) en México: las piezas del proyecto turístico de FONATUR. In Seminario Internacional de Investigación en Urbanismo. "VI Seminario Internacional de Investigación en Urbanismo, Barcelona-Bogotá, junio 2014. Barcelona.

Demajorovic, J., Aledo Tur, A., Landi, B., y Mantovani Kondo, A. L. (2011). Complejos turísticos residenciales: análisis del crecimiento del turismo residencial en el Mediterráneo español y en el Litoral Nordestino (Brasil) y su impacto socio-ambiental. Estudios y Perspectivas en Turismo, 20(4), 772-796.

Dos Santos, P. (2011). Marco Teórico Metodológico de los Estudios del Paisaje. Perspectivas de aplicación en la planificación del turismo. Estudios y Perspectivas en Turismo, 20, 522-541.

Fonatur. (n.d.). Proyecto de desarrollo turístico en Cancún, Q.R. México.

Fonatur. (1982). Cancún un Desarrollo Turístico en la Costa Turquesa. Cancún, México.

Fyhri, A., Jacobsen, J. K. S., y Tømmervik, H. (2009). Tourists' landscape perceptions and preferences in a Scandinavian coastal region. Landscape and Urban Planning, 91, 202-211.

Galacho, F. B., y Luque, A. (2000). La dinámica del paisaje de la Costa del Sol desde la aparición del turismo. Baética, Estudios de Arte, Geografía E Historia, 22, 25-58.

Garay, L., y Cànoves, G. (2011). Life cycles, stages and tourism history. The Catalonia (Spain) Experience. Annals of Tourism Research, 38(2), 651-671.

Giné, H. (2015). El uso del potencial natural de los paisajes como recurso turístico. Implicaciones medioambientales. Revista de Desarrollo Rural y Cooperativismo Agrario, 1, 115-126. 
Gómez Orea, D. (2002). Evaluación de Impacto Ambiental (2a Edición). Madrid, España: Ediciones Mundi-Prensa.

Hernández, F. M. (2009). Nuevas espacialidades y paisaje turístico. El neoexclusivismo en el litoral marítimo bonaerense, Argentina. Nadir: Rev. Electron. Geogr. Austral, 1(2), 44-59.

Iglesias, B., Anfuso, G., Uterga, A., Arenas, P., y Williams, A. T. (2018). Scenic value of the Basque Country and Catalonia coasts (Spain): impacts of tourist occupation. J Coast Conserv, 22, 247-261.

Inegi. (2010). Marco Geosestadístico Municipal 2010, versión 5.0. Retrieved from www. cuentame.inegi.org.mx

Ivars i Baidal, J. A., Rodríguez Sánchez, I., y Vera Rebollo, J. Fe. (2013). The evolution of mass tourism destinations: New approaches beyond deterministic models inBenidorm (Spain). Tourism Management, 34, 184-195.

LALI Iniciativa Latinoamericana del Paisaje. (2018). Todo es paisaje ... y tú, itambién haces parte! Retrieved February 18, 2019, from http://www.lali-iniciativa.com/2018/11/01/ todo-es-paisaje/

Lindón, A. (2007). La construcción social de los paisajes invisiblesdel miedo. En J. Nogué (Ed.), La construcción social del paisaje (pp. 217-240). Madrid: Biblioteca Nueva.

Lozoya, J. P., Sardá, R., y Jiménez, J. A. (2011). Beach Multi-Risk Assessment in the Costa Brava (Spain). Journal of Coastal Research, 61(Special Issue), 408-414.

Lozoya, J. P., Sardá, R., y Jiménez, J. A. (2014). Users expectations and the need for differential beach management frameworks along the Costa Brava: Urban vs. natural protected beaches. Land Use Policy, 38, 397-414.

Malvárez García, Gonzalo Pollard, J., y Domínguez Rodríguez, R. (2009). The Planning and Practice of Coastal Zone Management in Southern Spain. Journal of Sustainable Tourism, 11(2-3: Mediterranean Tourism: Impacts and Policy Responses), 204-223.

Manuel, D. (2006). Aproximaciones a la noción de paisaje en las culturas andinas de la américa. Complexus, Revista de Complejidad, Ciencia y Estética, 2(1), 58-90.

Meseger, M. (2010). Acondicionamiento carretera CV-102 en Vinaroz (Castellón). Retrieved from http://www.ciopu.com/

Millán, M. (2012). Percepción de la Planificación y Gestión de los Espacios Turísticos Litorales de la Región de Murcia. El Periplo Sustentable, 22, 37-70.

Moreno, A., y Becken, S. (2009). A climate change vulnerability assessment methodology for coastal tourism. Journal of Sustainable Tourism, 17(4), 473-488.

Nogué, J. (1989). Paisaje y Turismo, 35. Retrieved from http://dugi-doc.udg.edu// handle/10256/4101

Nogué, J. (2010, November 6). Sin paisaje no hay turismo. Diario de Ibiza. Ibiza. Retrieved from http://www.diariodeibiza.es/pitiuses-balears/2010/11/06/joan-i-font-paisaje-hay-turismo/443794.html

Oehmichen, C. (2010). Cancún: la polarización social como paradigma en un México Resort. ALTERIDADES, 20(40), 23-34.

Palafox, A., Madrigal, D., y Zizumbo, L. (2011). Apropiación, funcionalización y homogenización del espacio para el desarrollo turístico de Quintana Roo, México. Caderno Virtual de Turismo, Río de Janeiro, 11(2), 282-293. 
Paredes, O. A. (2013). Manifestación de Impacto Ambiental modalidad particular. Proyecto "Club Naútico Cancún." Cancún, México.

Pereira de Oliveira, J., Lüders Fernandes, D., y Stach, C. (2007). The urban landscape as a tourism resource: a study of the built landscape of Irati - PR as a tourism attraction. Turismo - Visao E Acáo, 9(1), 83-94.

Phillips, M. R., y Jones, A. L. (2006). Erosion and tourism infraestructure in the coastal zone: Problems, consequences and management. Tourism Management, 27, 517-524.

Rangel-Buitrago, N., Correa, I. D., Anfuso, G., Ergin, A., y Williams, A. T. (2013). Assessing and managing scener $y$ of the Caribbean Coast of Colombia. Tourism Management, 35, 41-58.

Ricci, S., Fernández, G., Valenzuela, S., y Castronovo, R. (2010). El Paisaje como Patrimonio: Análisis de sus Cualidades en Relación al Uso Turístico-Recreativo. Ciencia, 5(13), 7-24.

Rico-Amoros, A. M., Sauri, D., Olcina-Cantos, J., y Vera-Rebollo, J. F. (2013). Beyond Megaprojects?. Water Alternatives for Mass Tourism in Coastal Mediterranean Spain. Water Resour Manage, 27, 553-565.

Roca, E., Villares, M., y Fernández, E. (2011). Social Perception on Conservation Strategies in the Costa Brava, Spain. Journal of Coastal Research, 61(Special issue), 205-210.

Rodríguez, F. (1994). El impacto ambiental del turismo. In Desarrollo regional y crisis del turismo en Andalucía, Simposio hispano-francés (pp. 331-339). Almería.

Roger, A. (2013). Breve tratado del paisaje. Biblioteca Nueva.

Roig-Munar, F. X., Mir-Gual, M., Rodríguez-Parea, A., Pons, G. X., Martín-Prieto, J. Á., Gelabert, B., y Blázquez-Salom, M. (2013). Beaches of Ibiza and Formentera (Balearic Islands): a classification based on their environmental features, tourism use and management. Journal of Coastal Research, Supl. Special Issue, 2(65), 1850-1855.

Rudzewicz, L., y Lanzar, R. (2008). Ecoturismo y conservación de los ecosistemas. Reservas Particulares de Patrimonio Natural en Brasil. Estudios y Perspectivas en Turismo, 17, 226-245.

Sakellariou, S., Samara, F., Tampekis, S., Sfoungaris, I., y Christopoulou, O. (2016). The Environmental Pressures and Perspectives of Tourism on Coastal and Insular Zone. The Case of Greece. Nature Environment and Pollution Technology, 15(3), 1009-1020.

Santos, P. P., y Vilar, J. W. C. (2013). Territorial coastal tourism in Sergipano (Brazil). Estudios Y Perspectivas En Turismo, 22(1), 84-101.

Santos y Ganges, L. (2003). Las nociones de paisaje y sus implicaciones en la ordenación. CIUDADES, 7(2002-2003), 41-68.

Secretaría de Turismo. (2016). 4to Informe de Labores 2015-2016. México, D.F.

Semeoshenkova, V., y Newton, A. (2015). Overview of erosion and beach quality issues in three Southern European countries: Portugal, Spain and Italy. Ocean and Coastal Management, 118, 12-21.

Soares, I. A., Medeiros, C. S. C., y Sales Filho, A. (2014). Análise de paisagens turísticas da praia de Ponta Negra (Natal/RN) com a utilizaçao de indicadores de qualidade visual: una contribuçao para o turismo sustentável/analysis of touristic landscapes of the Ponta Negra beach (Natal/RN) with the use of visual. HOLOS, 30(1), 424-434.

Sotelo, J. A. (1992). Paisaje, semiología y análisis geográfico. Anales de Geografía de La Universidad Complutense, 11, 11-23. 
Sytnik, O., y Stecchi, F. (2015). Disappearing coastal dunes: tourism development and future challenges, a case-study from Ravenna, Italy. J Coast Conserv, 19, 715-727.

Talledos, E. (2012). La imposición de un espacio: de La Crucecita a Bahías de Huatulco. Revista Mexicana de Ciencias Políticas Y Sociales, Universidad Nacional Autónoma de México, Año LVII(núm. 216), 119-142.

Torruco, D., y González, M. A. (2012). Las playas de Quintana Roo: sus riesgos y vulnerabilidad. El Periplo Sustentable, 24, 155-172.

Uluapa Sr. (2011). ACLARANDO. Retrieved July 11, 2015, from https://aclarando.wordpress. $\mathrm{com} /$

Universidad del Caribe. (2011). Historia de Cancún Parte 3. Retrieved April 23, 2016, from https://www.youtube.com/watch?v=RMQPyMn33xy

Zuluaga, P. (2006). Una mirada al paisaje como recurso turístico. Revista Interamericana de Ambiente y Turismo, 2(2), 76-82. 